\title{
Training and Pedagogical Support for Newly Recruited Teachers in Accordance with Quality Assurance Standards
}

\author{
Ali Larguet \\ Faculty of Humanities and Social \\ Sciences \\ University of Bouira ,Algeria \\ a.larguet@univ-bouira.dz
}

Mohamed Aissaoui

Faculty of law

University of Bouira ,Algeria

m.aissaoui@univ-bouira.dz

Received 26/7/2018

Accepted 5/5/2019

\section{Abstract:}

The issue of the composition of researcher professors at Algerian universities has been discussed during several conferences, forums and seminars at the national level to coordinate efforts in this field, and these efforts resulted in the issuance of decision No. 932 of 28 July 2016 by the Ministry of Higher Education and Scientific Research, which specifies the methods of organizing pedagogical facilities for newly recruited professors. The research aims to enable the newly recruited professor during the period of internship to acquire knowledge and skills in university teaching.

A national committee has been established to supervise and follow up the pedagogical facilities programme for the Professor in accordance with decision No. 1636 of 29 October 2016, consisting of 27 members from various fields of higher education, and pursuant to decision No. 932, the Chairman of the National Committee was tasked with preparing a working ground based on Scientific, pedagogical and organizational aspects, and accordingly the content of the decision has been implemented and the training has been launched throughout the country from November 2016 to June 2017, and this training has been completed by an evaluation report through a field study to determine the responsiveness of faculty members and their institutions to this composition. This research will discuss the assessment based on the principles and standards of quality assurance in higher education.

Keywords: composition, pedagogical accompanying, assessment of composition, quality assurance. 


\section{التكوين والمرافقة البيداغوجية للأساتذة حديثي التوظيف وفق معايير ضمان الجودة}

\author{
محمد عبسوي \\ كلية الحقوق و العلوم السياسية \\ جامعة أكلي محند أولحاج - البويرة - الجزائر \\ m.aissaoui@univ-bouira.dz
}

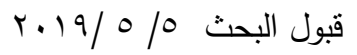

\author{
علي لرقط \\ كلية العلوم الإنسانية و الاجتماعية \\ جامعة أكلي محند أولحاج - البويرة - الجزائر \\ a.larguet@univ-bouira.dz
}

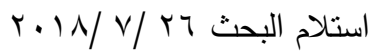

لقد تم بحث موضوع تكوين الأساتذة الباحثين بالجامعات الجزائرية خلال عدة مؤتمرات وملتقيات وندوات على مستوى الوطن للتنسيق بين

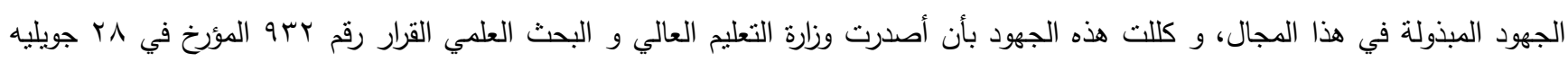

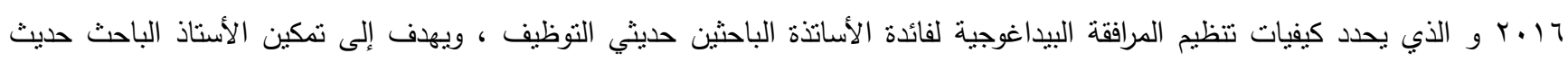

$$
\text { التوظيف خلال فترة التربص من اكتساب معارف و مهارات في فن التدريس الجامعي. }
$$

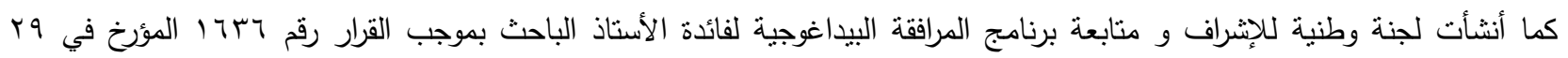

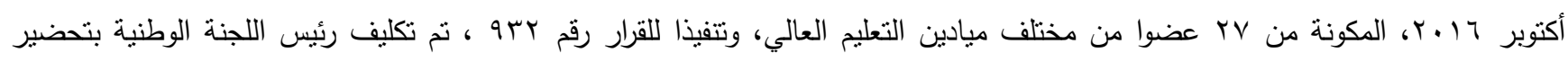

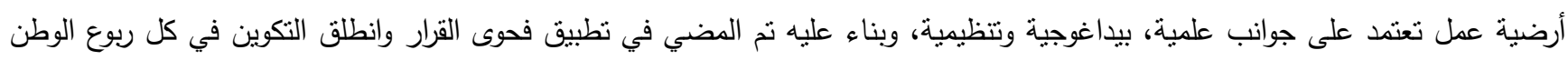

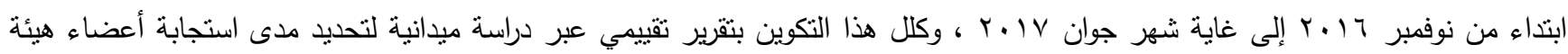
التذريس و مؤسساتهم لهذا التكوين، و الورقة الحالية تتناول هذا التقييم الذي بني على أسس ومعايير ضمان التين الجودة في التعليم العالي. الكلمات المفتاحية: النكوين، المرافقة البيداغوجية، تقييم النكوين، ضمان الجودة.

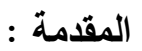

جودة التعليم. حيث تنطوي على أساليب فعالة لتخطيط وإعداد

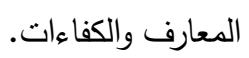

و قد اعتمد في هذا التقييم على سبعة محاور أساسية تتمثل فيما يلي:

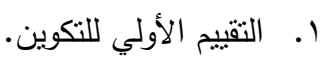
r. ب. تقيبم محتوى التكوين. r. تقييم المقاربات البيداغوجية المتبعة. ع. التقييم البيداغوجي للتكوين. ه. التقييم المنهجي للتكوين.

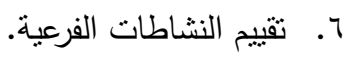
V. النقييم النهائي النكوين.

وختم هذا التقييم بإناحة الفرصة للمؤسسات حتى تعطي رأيها في هذا النكوين عبر أسئلة مفتوحة وأخرى مغلقة.
المبادئ التوجيهية لبرنامج التكوين موضحة في القرار رقم r وبه

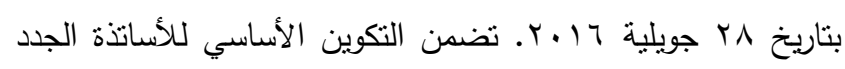

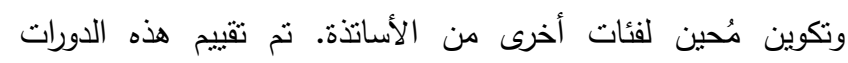

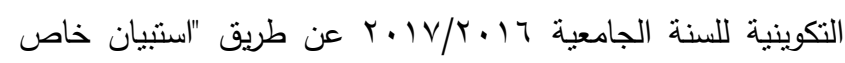

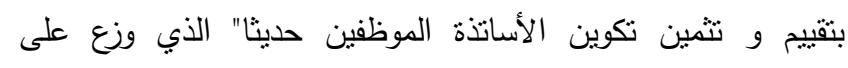

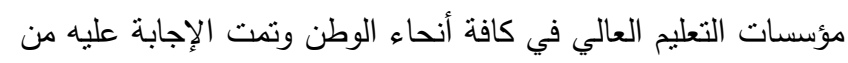
طرف منسقي خلايا التكوين للمؤسسات.

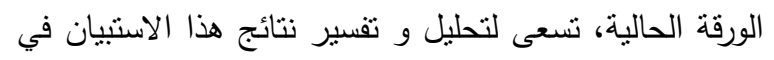
ضوء برنامج التكوين البيداغوجي الذي وضعته الوزارة الوصية في فئي متتاول مؤسسات التعليم العالي لتأطير هذه الثريحة من الموظفين.

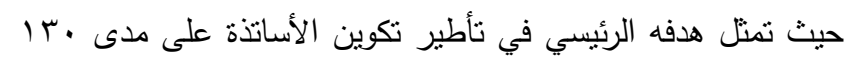

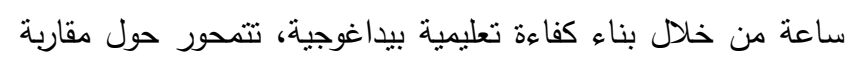
ترتكز على تعلم مهنة الأستاذ الباحث، لاكتساب المهارات والكفاءات

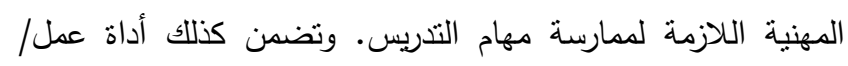

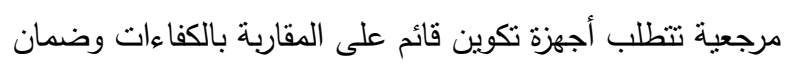


التوظيف). باعتبارهم حديثي عهد بمهنة التدريس؛ بهدف نمكينه ممن

الاندماج في مهنة التدريس وفي الحياة الجامعية' . تقييم التكوين: هو عملية " قياس مدى التأثير الذي تركه التكوين على المتدربين، (الأساتذة حديثي التوظيف) وكمية التحصيل التي خرجوا بها من العملية التدريبية، في الجانب المنهجي والمحتوى البيداغوجي ومختلف النشاطات الفرعية التي اكتسبوا من خلالها جملة من المعارف والمهارات والاتجاهات الجديدة، وهي كذلك معرفة الأثز الناتج عن الدورة التكوينية، ومقارنتها مع الأهداف المسطرة في مرحلة التخطيط'.

نظام ل م د:' LMD (ليسانس، ماستر، دكتوراه) وهو نظام يستجيب لضروريات عولمة المعارف برفع مستوى التعليم العالي. يرمي هذا النظام إلى الأهداف التالية : تتظيم عروض التكوين على شكل مسالك متتوعة للطالب، الذي يستفيد من المرافقة و التوجيه من قبل الأستاذ

$$
\text { (الوصي) (1اب) }
$$

تحسين النوعية البيداغوجية، الإعلام، التوجيه ومرافقة الطالب.

تطوير التمهين في الدراسات العليا. تفضيل تعلم القدرات العرضية (التمكن من اللغات الأجنبية الحية، إستعمال الإعلام الآلي والأنترنت).

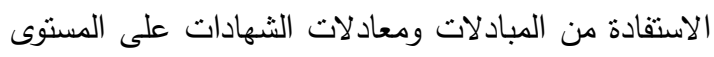

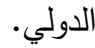

نظام ل.م.د يشمل r شهادات، بتحصيل متدرج: الليسانس يوافق 7 سداسيات من الاراسة، الماستر توافق ع سداسيات دراسة إضافية، دكتوراه توافق 7 سداسيات من الدراسة والبحث بعد الماستر .

\section{البرنامج الوطني المعتمد في عملية التكوين:}

مهنة الأستاذ الباحث تتطلب اثثين من المهارات التكميلية اللازمة لأداء مهمته على نحو مُرضٍ بالجامعة. بالإضافة إلى عالى مشاركته الفعالة في مجال البحث العلمي، يجب أن يسعى كذلك بشكل دائم لتحسين وتطوير أساليب نقل المعرفة لطلبته. هذه المهمة الأساسية التي تهدف لإعداد إطارات وباحثي المستقبل، تتطلب من الأساتذة الإعداد الجيد واكتساب زاد معرفي بيداغوجي. الخطة التكوينية للأساتذة الباحثين، التي جاءت بمبادرة من الوزارة الوصية تتكفل بتحقيق هذا الهدف نظرا لما يكتسبه من أهمية كبيرة. وفي هذا الإطار تتظم على مستوى كل مؤسسات التعليم العالي مرافقة بيداغوجية لفائدة الأستاذ الباحث حديث التوظيف تهدف إلى تمكينه خلال فترة التربص من اكتساب معارف و مهارات في فن التدريس الجامعي. بحيث تتظم دورات وحصص تدربيية تشمل لا سيما:

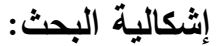

أصدرت وزارة التعليم العالي و البحث العلمي القرار r rو

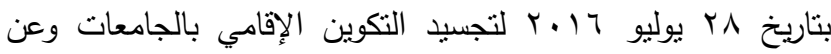
بُعد، بعد أن أرست هيئة وطنية لضمان الجودة في التعليم العالي حتى بنى يتكامل برنامج الإصلاح الثامل للمؤسسات الجامعية، ويُعتبر هذا التكوين الأولَ من نوعه منذ استقلال البلاد سنة ب79 19، وتأتي هذه الأه الورقة البحثية لرصد واقع هذا التكوين في دورته الأولى لأعضاء هيئة

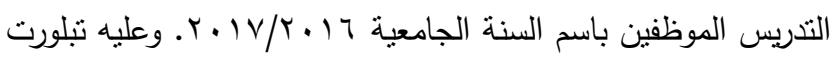
تساؤلات البحث على النقاط التالية:

ما واقع تطبيق مضمون القرار رقم بسو المتضمن كيفية

$$
\text { النكوين؟ }
$$

هل هناك معوقات تطبيق مضمون القرار رقم المتضمن كيفية التكوين؟ ما هي المقترحات إزاء هذه المعوقات؟ أهداف البحث: التعرف على:

واقع تطبيق مضمون القرار رقم بrq المتضمن كيفية

$$
\text { التكوبن. }
$$

المعوقات تطبيق مضمون القرار رقم بrq المتضمن كيفية التكوبن المقترحات إزاء هذه المعوقات.

\section{أهمية البحث:}

تكمن أهمية هذه الورقة البحثية في كونها محطة تقويمية ضرورية لوزارة التعليم العالي و البحث العلمي، حتى تتخذ كل التدابير اللازمة دن أجل تحسين و تطوير تكوين الأساتذة أعضاء هيئة التدريس الجدد للاضطلاع بمهنة التدربس وفق منظور السياسة العامة لبرنامج الحكومة الذي يعتمد على النوعية و الجودة و الحكامة.

\section{المصطلحاث الإجرائية للبحث:}

ضمان جودة التكوين: هي عملية تقييم مبرمجة للتأكد من أن مقاييس التكوين و البحث و كذللك الهياكل و التكفل بأعضاء هيئة التدريس، محترمة متابعة ومنفذة. تقوم بذلك لتحقيق المهام وضمان للأطراف المشاركة الداخلية و الخارجية، أنها تقود عمليات تحسين متواصل لجميع الأنشطة الخاصة بالتكوين وفق مرجعية تعتمد على

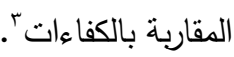
المرافقة البيداغوجية (التريوية): يتجه هدف المرافقة البيداغوجي نحو الممارسة المهنية القائمة على منطق المرافقة والتأطير ، و ذلك من أجل ضمان أداء أفضل يسمح بتجاوز الصعاب وضمان نتائج حسنة في ميدان مهنة التدريس، وتدعم هذه العملية البعد التعاقدي في العلاقة بين المرافِق البيداغوجي (المكوِن) و المرَافَق (الأستاذ حديث 
طبلة فنرة تكوبنهم وفق معايير النوعية و ضمان الجودة التي اعتمدتها وزارة التعليم العالي و البحث العلمي بالجزائر.

الهدف من المرجع: (المرجع الخاص بكفاءات الأساتذة) ا. الهرف العام: يهدف هذا المرجع إلى توضيح أهداف وغايات التكوين من ناحية الكفاءات المهنية المتوقعة والمنتظرة من الأستاذ-الباحث حديث التوظيف بهرف جعل نشاطه التعليمي من أكفأ ما يكون وفي السياق المناسب. إذ يمنح إطارا خاصا لنوعية وجودة المرافقة البيداغوجية للأساتذة.

r. . أهداف خاصة: يهدف هذا المرجع إلى : بلى دعم المرافقة البيداغوجية من زاوية مهنية ناجحة، فعالة وكُفُؤة.

إدماج مختلف المعارف المتحصل عليها من طرف الأستاذ ما يسمح له بانجاز كامل مهامه التعليمية. إدارة أفضل لمسارات تكوين الأساتذة.

اكتساب وتعزيز ثقافة الجودة في مسار تكوين الأساتذة. تحسين الوسائل المنتظر تطويرها من طرف المؤسسات التعليمية باللجوء إلى الموارد المتوفرة من كل المستويات.

\section{الكفاءات الأساسية المستهرفة:}

ك ا ـ الأستاذ الباحث يتحكم في الوسائل التعليمية الكلاسيكية والحديثة. ك؟ بـ يضمن الأستاذ- الباحث المناخ المعرفي الملائم لمسار التعليم. كآـ إدراك أهمية الحوار البيداغوجي. كـ.إضفاء ديناميكية من أجل تطوبر قدرات الطالب (تحفيز على لئ (العصامية).

كه. استعمال تقنيات تتشيط الفريق في الحالة البيداغوجية (أعمال موجهة، أعمال تطبيقية، تربصات). كَ7. التعود على العمل التعاوني ضمن اللجان البيداغوجية وفرق التكوين.

كىV. التدريب على ممارسة الإشراف و مرافقة الطلبة (التربص). كی. التحكم في التعبير الثفهي والكتابي في وضعيتي التعليم و البحث.

كو. تطوير المبادرات و الابتكار في مجالي المعرفة و المهارة. ك . 1 ـ تحديد قدرات العمل البيداغوجي. ك ا1 . التقييم الجماعي و الفردي للتطور الحاصل في اكتساب المعرفة، المهارة واللباقة. كץ ا. . استعمال شبكة التقييم المتعلقة بأهداف المخطط التكويني للمؤسسة.
(البرنامج الوطني للتكوين) تدريس مبادئ التشريع الجامعي، مدخل للتعليمية و البيداغوجيا، علم النفس و علم النفس التربوي، كيفيات تصميم الدروس و إعدادها و الاتصال البيداغوجي، كيفيات تقييم الطلبة، التعليم عن بعد، استعمال تكنولوجيا الإعلام و الاتصال في

التدريس.

الجدول رقم ( 1 • ) البرنامج الوطني للتكوين المقترح من طرف الوزارة الوصية.

\begin{tabular}{|c|c|}
\hline ح- س & الموضوعات \\
\hline 3 & حصة التعارف، سياسة وهدف التكوين الجامعي. \\
\hline 3 & التعليم، التكوين والعلاقات الإنسانية. \\
\hline 10 & الطالب. البيداغوجيا وعلم النفس البيداغوجي في التكوين - التدريب عند \\
\hline 5 & والتواقع. \\
\hline 5 & والتعليمية. والتكوين ضمن نظام ل لم.د.الخصائص البيداغوجية \\
\hline 10 & تقنيات تتشيط فرق التكوين والإثراف. \\
\hline 5 & تقنيات البحث الببليوغرافي وإعداد وثائق تلائم المسار التكويني. \\
\hline 10 & تقييم وإعداد شبكات الكفاءات. \\
\hline 15 & تقنيات الإعلام والاتصال الأدوات الرقمية. \\
\hline 5 & طرق ووسائل التعليم وتقنيات الإعلام والاتصال. \\
\hline 5 & ورقة الطريق لمشاريع الطالب. \\
\hline 5 & شقيكات التقييم). \\
\hline 10 & حصص تعليم اللغة- مركز التعليم المكثف للغات. \\
\hline 10 & تقتيات التعبير الكتابي ونموذج عن التقرير العلمي. \\
\hline 10 & طرق وكيفيات إعداد برامج تكوين ذات الجودة ونوعية جيدة. \\
\hline 5 & إعداد برنامج التكوين، التعليم والمحيط. \\
\hline 5 & دفتر الثروط وورقة الطريق في النشاط التكويني. \\
\hline 1 & المسؤولية المعنوية والتمهينية للجامعة. \\
\hline 1 & دور ومهام البحث. \\
\hline 5 & الأخلاق والآداب في التعليم الجامعي-السهر البيداغوجي. \\
\hline 1 & الغاية من التكوين الجامعي. \\
\hline 1 & 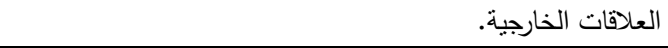 \\
\hline 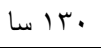 & 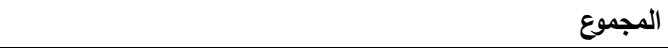 \\
\hline
\end{tabular}

\section{المرجع الخاص بكفاءات الأساتذة -الباحثين حديثي التوظيف:}

تعتبر مهنة التدريس من المهن المكتسبة، فأيا كانت الكفاءات المرتبطة بالتخصصات، لا يمكننا أن نفوض لأنفسنا أن نكون أساتذة، دون المرور بفترة نكوين منهجي وتربوي عميق. وهو الهدف الذي تصبو إلى تحقيقه الوزارة الوصية بعد ظهور القرار رقم rسه المؤرخ

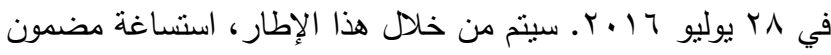
القرار بهدف تتفيذ التوجيهات والتوصيات التي أتى بها، بهدف تدعيم مؤسسات التعليم العالي بكامل المهارات التي استفاد منها الأساتذة 
أغلبهر جامعات كبرى و البقية موظفون في OV مؤسسة جامعية

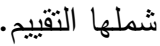
الجدول رقم (ץ •): توزيع المؤسسات الجامعية حسب عدد الأساتذة الجدد.

\begin{tabular}{|c|c|c|}
\hline النسبة & التكرار & عدد الأساتذة \\
\hline Tr, & ro & $\mid r-r$ \\
\hline IT,rr & 1. & Yo-1 $\leqslant$ \\
\hline$r, r r$ & 17 & $r V-r Y$ \\
\hline $1 T, r T$ & 1. & $\sum q-r \wedge$ \\
\hline$\wedge, \cdot \cdot$ & .7 & $71-0$. \\
\hline $7,7 \wedge$ & .0 & $V T-T r$ \\
\hline$\varepsilon, \ldots$ &.$r$ & $\Lambda Y-V \leqslant$ \\
\hline $1 \ldots$ & vo & المجموع \\
\hline
\end{tabular}

ثنانيا: عرض و تحليل لمحاور الاستبيان: 1. تكرارات الإجابات على أسئلة التقييم الأولي للتكوين. الجدول رقم (ع ·): يوضح نتائج البيان الأولي للتكوين.

\begin{tabular}{|c|c|c|c|c|c|c|}
\hline \multicolumn{5}{|c|}{ درجات التقييم } & \multirow{2}{*}{\multicolumn{2}{|c|}{ المعايير }} \\
\hline جيد جدا & جيد & صحيح & غير مرض & ضعيف & & \\
\hline$r v$ & TV & v & $r$ & 1 & التكرار & التحاق المشاركين \\
\hline $0 ., 71$ & rv & 9,7 & $r, V \varepsilon$ & 1 & النسبة & بالتكوين \\
\hline v & $r r$ & iv & ru & 7 & التكرار & مدى إدراك \\
\hline 9,09 & $r \cdot, l \varepsilon$ & $r r, r q$ & $r \Lambda, V Y$ & $\Lambda, Y r$ & النسبة & ل ل م مدين لنظام \\
\hline$\varepsilon$ & 11 & ro & r & 1. & التكرار & مدى إدراك \\
\hline $0, \sum \wedge$ & $10, \cdot V$ & $r \varepsilon, r_{0}$ & $r, 01$ & $I r, v$ & النسبة & للمقاربة بالكفاءات المشاركين \\
\hline 7 & 9 & r & $r r$ & ir & التكرار & مدى معرفة \\
\hline$\Lambda, r r$ & Ir,Tr & $r 1,01$ & r1,01 & $17, \varepsilon \varepsilon$ & النسبة & بالنصوص الشاركين \\
\hline
\end{tabular}

السؤال الأول: التحاق المشاركين بالتكوين: من خلال الجدول يتضح أن نسبة المشاركة المبئية في التكوين معتبرة حيث إنّ من بين VT مؤسسة هناك ع I مؤسسة جامعية كانت مشاركتها جيدة و جيدة جدا ، وهذا يعكس المشاركة العامة الفعلية التي هني صرحت بها المؤسسات و التي بلغت r •, ب9\% حسب جدول البيانات التفصيلي. كما أن 9 . مؤسسات جامعية كانت استجابتها بين صحيح و غير مُرض وهذا راجع لبعض الغيابات الراجعة للعطل المرضية و الأمومة وطبيعة الجغرافيا في بعض مناطق الوطن والأعباء الإدارية كما صرح بذللك منسق خلايا التكوين في نقاريرهم. و الجدير بالذكر التهر

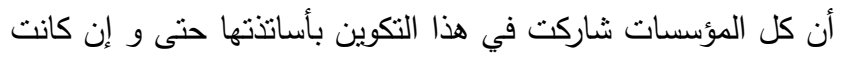
مشاركة ضئيلة و ذللك ما تبينه الاستجابة (ضعيف) التي كانت نسبتها

السؤال الثاني: مدى إدراك المشاركين لنظام ل.م. د:

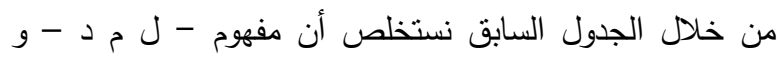

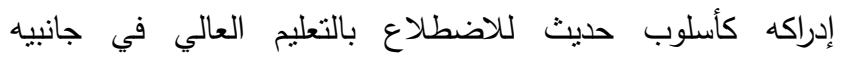
البيداغوجي و البحث العلمي مازال في بداية هذا التكوين و يحتاج إلى لإلى لإلى مجهودات كبيرة حتى يكون واضحا في أذهان الأساتذة حديثي
تقييم و تثمين تكوين الأساتذة الموظفين حديثا (أداة جمع

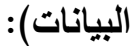

اعتمد الباحثان على أداة الاستيان لجمع البيانات لتقييم التكوين، المصمم من طرف اللجنة الوطنية لتقييم و متابعة المرافقة البيداغوجية للأساتذة حديثي التكوين، وقد كلفا من طرف اللجنة بتطبيق الانتبيان وتوزيعه على كافة مؤسسات التعليم العالي. و

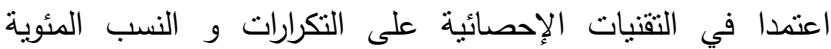

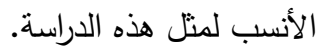

أولا: خصائص الثبكة الجامعية المعنية بالتقييم: 1. توزيع المؤسسات الجامعية حسب النوع وعدد الأساتذة حليثي التوظيف:

الجدول رقم (ץ •): توزيع المؤسسات الجامعية حسب النوع.

\begin{tabular}{|c|c|c|c|c|}
\hline نسبة الحضور & عدد الأساتذة & النسبة المئوية & التكرار & نوع المؤسسة \\
\hline 94,79 & INTO & $00, \wedge \varepsilon$ & $r \varepsilon$ & جامعة \\
\hline דז,ז9 & rro & $r_{0, .} T$ & rV & مدرسة \\
\hline 19 & 4r & 9,1 . & $\cdot v$ & مركز جامعي \\
\hline$q r, \cdot r$ & r) & $1 \ldots$ & $V V$ & المجموع \\
\hline
\end{tabular}

تضم الشبكة الجامعية الجزائرية مئة وستَّ (7 + () مؤسسات للتعليم العالي، أرسلت VV مؤسسة جامعية تقاريرها و استبياناتها و ذللك يعادل ما نسبته ع \&YY,T من مجموع الثبكة الجامعية

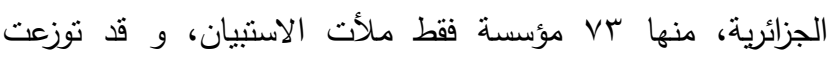

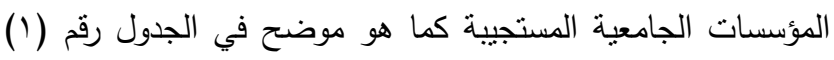
حسب طبيعتها إلى بـ جامعة و التي تشكل أكبر نسبة بحضورها في عملية تقييم هذا التكوين، ذلك لأن عددها الفعلي عبر ولايات الوطن

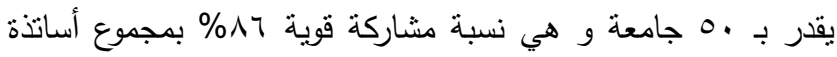

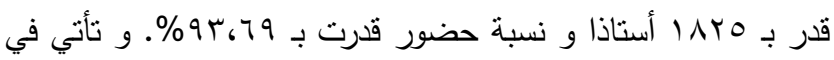

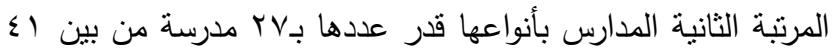

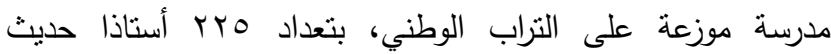

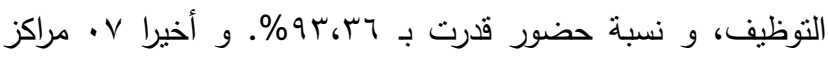

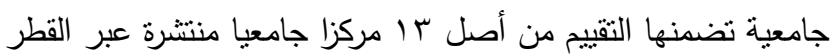
الجزائري، أي أكثر من النصف بتعداد بـا أستاذا حديث التوظيف و

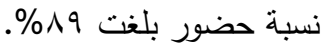

\section{r. ت توزيع المؤسسات الجامعية حسب عدد الأساتذة الجدد:}

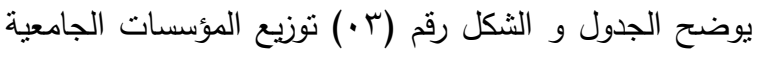

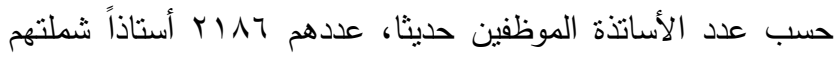

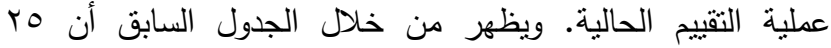
مؤسسة جامعية يتراوح فيها عدد الأساتذة الموظفين حديثا بين ب و وسا

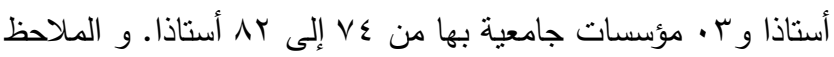

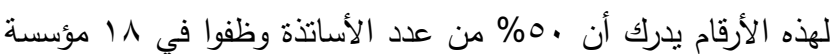


r. تكرارات الإجابات على أسئلة تقييم محتوى التكوين.

الجدول رقم (ه .): يوضح الإجابات على أسئلة تقييم محتوى التكوين.

\begin{tabular}{|c|c|c|c|c|c|c|}
\hline \multicolumn{5}{|c|}{ درجات التقييم } & & \multirow[b]{2}{*}{ المعايير } \\
\hline جيد & جيد & صحيح & مرض & ضعيف & & \\
\hline 11 & r & 14 & 7 & I & التكرار & \multirow{2}{*}{ تتظيم الدروس } \\
\hline$r \leq, 74$ & $\{0, Y\}$ & Y1.9Y & A.rY & 1 & النسبة & \\
\hline 10 & $\leqslant r$ & $1 \varepsilon$ & r & 1 & النكرار & \multirow{2}{*}{ المحتويات نطابق } \\
\hline$r .00$ & Or.or & 19611 & T.V $\varepsilon$ & 1 & النسبة & \\
\hline $1 \%$ & YT & r. & $\varepsilon$ & $r$ & التكرار & \multirow{2}{*}{ الدفاية توزيع } \\
\hline$\left|V_{6} \wedge\right|$ & T1.01 & $\{1,1$. & $0, \varepsilon \wedge$ & \{.।1 & النسبة & \\
\hline$r$. & rY & IV & $r$ & 1 & التكرار & \multirow{2}{*}{ الألمعتوى ملائمة } \\
\hline TY $V_{6} \varepsilon$. & $\varepsilon r_{6} \wedge \varepsilon$ & rr, & E.11 & $1, \pi \mathrm{V}$ & النسبة & \\
\hline
\end{tabular}

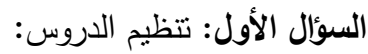

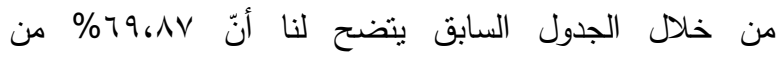

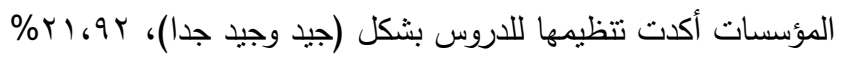

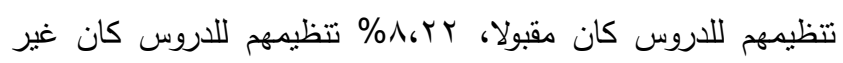

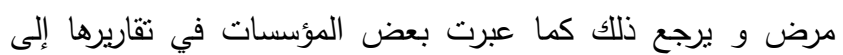
ضيق وقت الدورة التكوينية وعدم مناسبة نوقيتها بالنسبة للأساتذة المتربصين، كونها جاءت في فترة الذروة البيداغوجية.

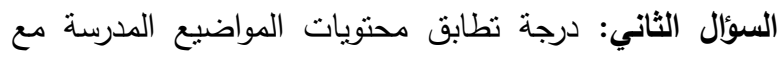

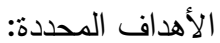
يوضح الجدول السابق أن محتويات المواضيع المدرسة والأهداف

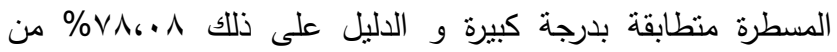

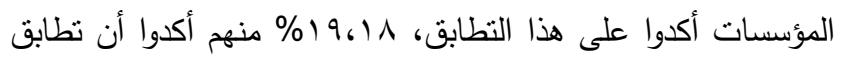

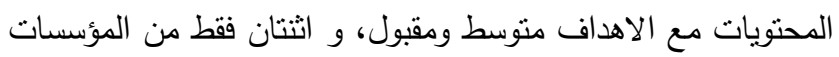
أنشارنا إلى ضعف هذا التطابق. السؤال الثالث: كفاية توزيع المقرر و نتابع الدروس: من خلال الجدول السابق يمكن القول إنّ هناك تتوعاً في نوزيع و لتوريع

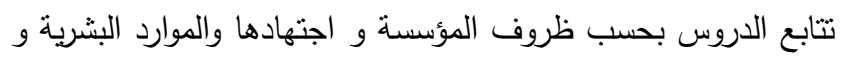
المادية التي تنتلكها، بr، ه0\% توزيعهم للاروس كان يندرج في فئة جيد و جيد جدا، وقد تم توزيع برامج التكوين على مدار السنة بنسبة

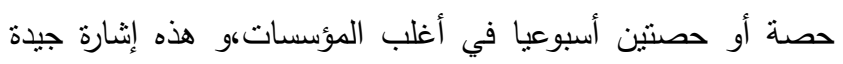

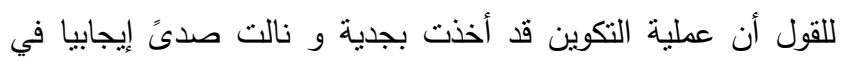
أوساط المؤسسة الجامعية، في انتظار التحاق باقي المؤسسات التي تحاول اللحاق بركب الجامعات المتميزة.
التوظيف، V، Y، \% فقط يدركون ل م د بشكل جيد و جيد جدا،

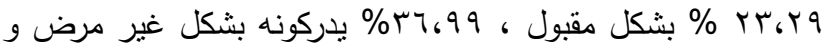
ضعيف، ذلك بالرغم من أن برنامج النكوين خصص مد محاور مفصلة

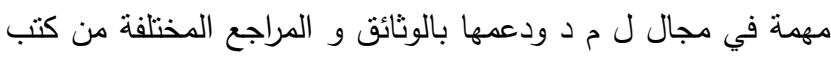
و نصوص قانونية و دروس عبر وسائط تكنولوجية. و من خلال

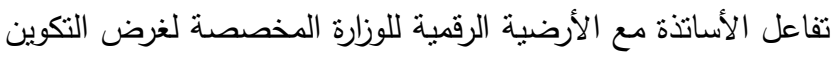

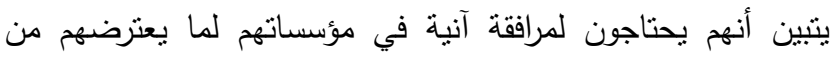

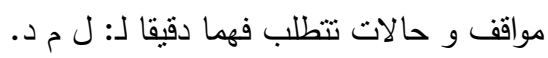
السؤال الثالث: مدى إدراك المشاركين للمقاربة بالكفاءات: يستعرض الجدول السابق نتائج أولية عن مدى إدراك و فهر الأساتذة للمقاربة بالكفاءات التي تبنتها الوزارة الوصية كمقاربة إجرائية

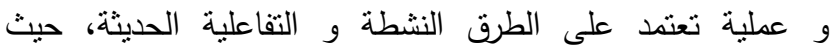
00, •r\% من الأساتذة بدركون مفهوم المقاربة بالكفاءات بكيفية جيدة

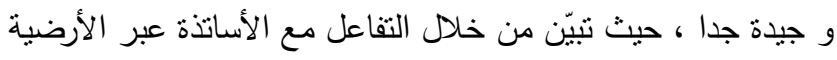

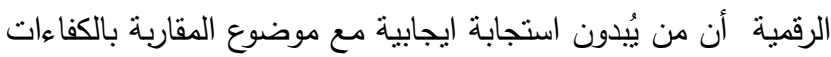
أغلبهم من كان تكوينهم القاعدي و شهاداتهم في مجال التربية و التعليم و علم النفس و علم الاجتماع و تعرضوا لطرق و و استراتيجيات التدريس الحديثة. والذين كانت استجابتهم مقبولة على العموم نسبتهم

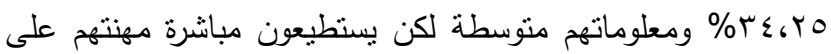

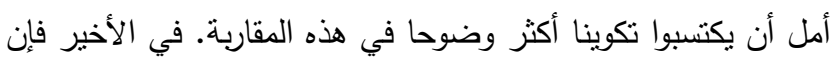

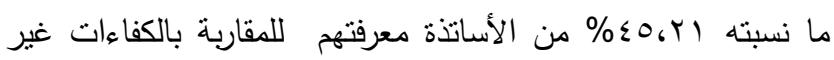
مرضية و ضعيفة و هي نسبة معتبرة قد ترجع إلى غياب هذا المفهوم

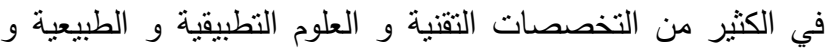

السؤال الرابع: مدى معرفة المشاركين بالنصوص:

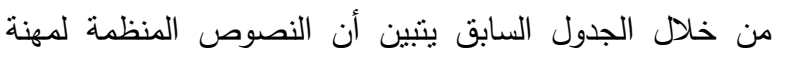
التدريس و ل م د و البحث العلمي و غيرها لبست معروفة بالثكل المرغوب في بداية هذا التكوين ، حيث

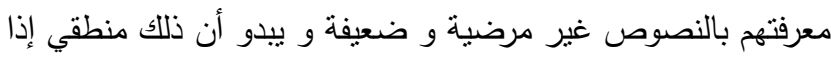
سلمنا بكثرة النصوص و القوانين المنظمة وتنسارع صدورها وإلغاء

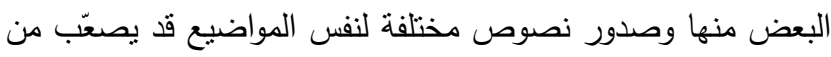
التعرف عليها و فهمها كاملة. أما الذين يعرفون تللك النصوص بصنفة جيدة و جيدة جدا فبلغت نسبتهم 00، •r\% فقط أي خمس العدد

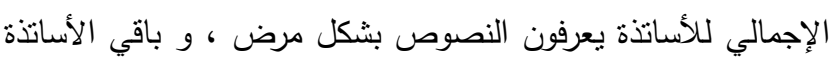

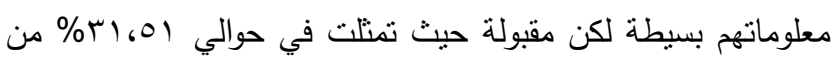
العدد الكلي للأساتذة ممن يعرفون النصوص بشكل منوسط. و تعثبر

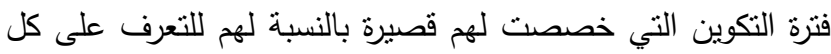

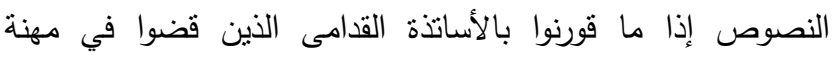

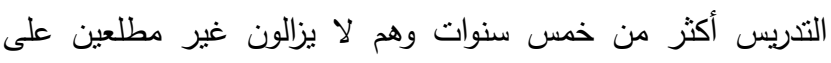
الكثير من النصوص. 
المؤسسات تقدرها بشكل جيد و جيد جدا، و أن أكثر من ·r\% منها

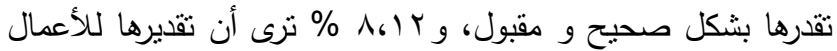
النطبيقية بالنسبة لأهداف التكوين ضعيف و غير مرض ، هيث

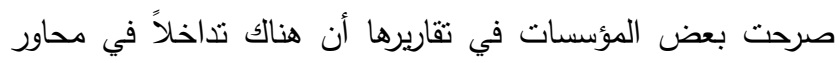
التكوين و هذا جعل تجسيده على أرض الواقع فيه بعض الصعوبة. السؤال الثالث: تقدير الإنجاز الثخصي للمشاركين:

الجدول السابق يوضح مدى تقدير المؤسسات الجامعية للإنجاز

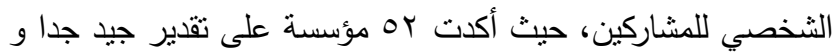
جيد لمشاركة أساتنتها حديثي التوظيف بإنجازات ومبادرات شخصية، و هذا فيه دلالة على أن انخراط الأساتذة في النكوين في هذه المؤسسات كان مميزا و إيجابيا، 11 مؤسسة كان تقديرهم لهذه

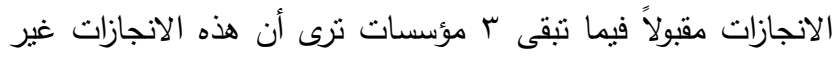
مرضية. السؤال الرابع: تقدير العروض المقدمة من طرف المشاركين

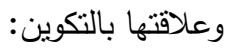

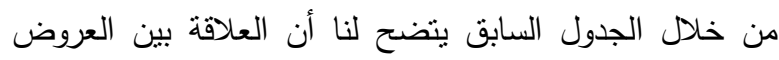

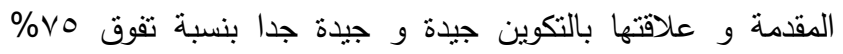
حسب استجابة 00 مؤسسة جامعية، وهي نسبة معتبرة تتم عن وعي ودراية واضحة لمحتويات التكوين و نشاطاته وإدراك الأهداف المحددة،

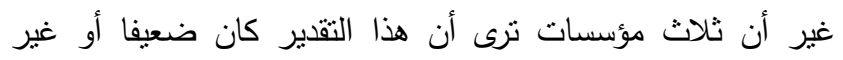
مرض و ربما يرجع ذلك إلى نقص عدد المكونين لتغطية محاور

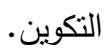

السؤال الخامس: تقدير و تطابق النشاطات التعليمبة: النشاطات التعليمية كانت منطابقة إلى حد كبير في نظر أغلب

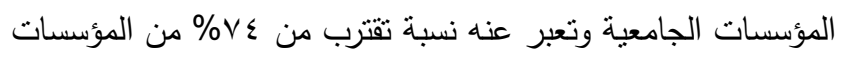

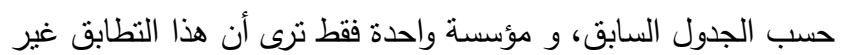
مرض، و قد يرجع السبب إلى عدم فهم هذا السؤال.

؛. تكرارات الإجابات على أسئلة التقييم البيداغوجي للتكوين.

الجدول رقم (v •): يوضح الإجابات على أسئلة التقييم البيداغوجي للتكوين.

\begin{tabular}{|c|c|c|c|c|c|c|}
\hline \multicolumn{6}{|c|}{ درجات التقييم } & \multirow[b]{2}{*}{ المعايير } \\
\hline جيد & جيد & صحيح & غرض & ضعيف & & \\
\hline IV & \&1 & $1 \varepsilon$ & 1 & 1 & النكرار & \multirow{2}{*}{ تلتكوق الأهداف المحددة } \\
\hline rT,rq & 07,17 & 19,11 & I.rV & 1 & النسبة & \\
\hline$r$. & $r \varepsilon$ & 10 & $\varepsilon$ & 1 & التكرار & \multirow{2}{*}{ إلجراءرة من تقييم الكفاءات } \\
\hline «1,1. & rr,AN & $r .000$ & $0, \varepsilon \wedge$ & & النسبة & \\
\hline IT & ro & r. & 7 & 1 & النكرار & \multirow{2}{*}{ 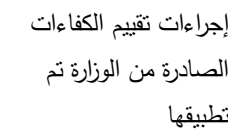 } \\
\hline $17 . \leqslant \varepsilon$ & $\varepsilon V_{6} 90$ & $r V_{6} \varepsilon$. & A.rY & 1 & النسبة & \\
\hline rr & ro & $1 \varepsilon$ & r & 1 & التكرار & \multirow[t]{2}{*}{ المناخ ملائم للتكوين } \\
\hline$r \cdot \sigma) \varepsilon$ & $\varepsilon V_{1} 90$ & 19.11 & $r_{6} V \leqslant$ & 1 & النسبة & \\
\hline
\end{tabular}

السؤال الرابع: مستوى ملاءمة الدروس و الأعمال التطبيقية مع

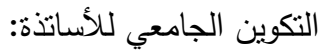

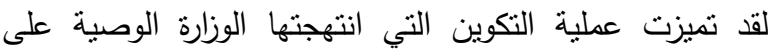
المقاربات الحديثة في التدريس و هذا جعل أغلب المؤسسات الجامعية متفائلةً إزاء محتويات التكوين لأنها تلائم بشكل كبير ما بحتاج إليه

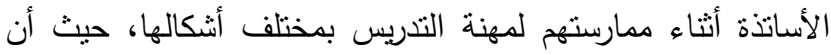

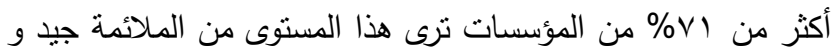

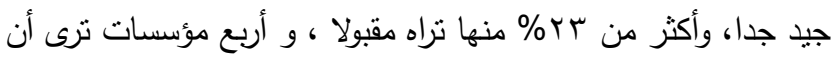
هذا المستوى غير مرض أو ضعيف، و قد يرجع ذلك إلى طبيعة هذه المؤسسات التي تعودت على التنريس بالطرق التقليدية التي تفتقر إلى البيداغوجيا النشطة التي تجعل من المتعلمين محورا أساسيا في عملية

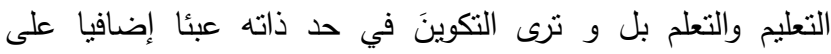
المؤسسة الجامعية.

\section{r. تكرارات الإجابات على أسئلة تقييم المقاريات البيداغوجية}

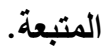

الجدول رقم (؟ •): الإيجابات على أسئلة تقييم المقاريات البيداغوجية المتبعة.

\begin{tabular}{|c|c|c|c|c|c|c|}
\hline \multicolumn{5}{|c|}{ درجات التقييم } & \multirow{2}{*}{\multicolumn{2}{|c|}{ المعايير }} \\
\hline جيد & جيذ & صحيح & غرض & ضعيف & & \\
\hline ir & rr & צr & 1 & 1 & الت التكرار & كفاية عدد النشاطات \\
\hline $17 ، \leqslant \varepsilon$ & $\{0, Y)$ & ro, & $1, \mathrm{TV}$ & $1, r v$ & النسبة & الترجوة من التكوين لتحقيق الأهداف \\
\hline 9 & צ & rr & 0 & 1 & 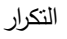 & تقدير الأعمال التطبيقية \\
\hline אזr Tו & $\sum q, r r$ & $\Gamma \cdot.) \leq$ & 7,10 & $1 . \mathrm{rV}$ & النسبة & بالنسبة لأهداف التكوين. \\
\hline ir & rq & 11 & r & 1 & الت التكرار & تقدير الانجاز الثخصي \\
\hline$\left|V_{6} A\right|$ & or، $\varepsilon r$ & $r \leq 677$ & 纟611 & 1 & النسبة & للمشاركين \\
\hline $1 \leq$ & «1 & 10 & r & 1 & 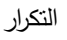 & تقدير العروض المقدمة \\
\hline 19.11 & 07.17 & $r ., 00$ & T.V $\varepsilon$ & $1, r V$ & النسبة & وعل طرف المشاركين \\
\hline ir & $\leqslant r$ & 11 & 1 & l & الت التكرار & تقدير و تطابق النشاطات \\
\hline $17 ، \leqslant \varepsilon$ & ov,or & $r \leq 677$ & $1, \mathrm{TV}$ & I & النسبة & التعلمية \\
\hline
\end{tabular}

السؤال الأول: كفاية عدد النشاطات التعليمية لتحقيق الأهداف

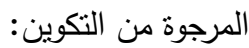

بطلعنا الجدول السابق و المضلع التكراري أن أكثر من آبرة من المؤسسات الجامعية ترى أن كفاية عدد النشاطات التعليمية لتحقيق الأهداف المرجوة من التكوين بين جيدة و جيدة جدا و هذا دليل على فهمه لتلك النشاطات الموضحة في برنامج التكوين و

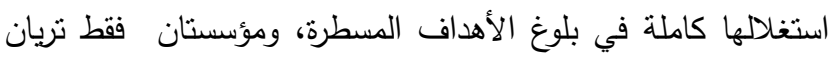
أنه ليست هناك كفاية مرضية بل ضعيفة. السؤال الثاني: تقدير الأعمال التطبيقية بالنسبة لأهداف التكوين: يوضح الجدول السابق درجة تقدير الأعمال التطبيقية بالنسبة

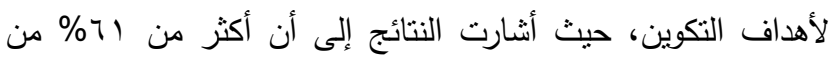


المجلة الدولية لضمان الجودة - المجلد الثاني - العدد الأول، 9 ـــ.

السؤال السادس: ملائمة المواضيع لاحتياجات الطلبة:

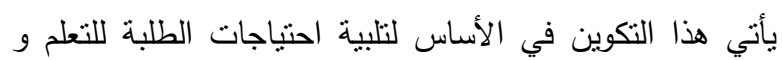

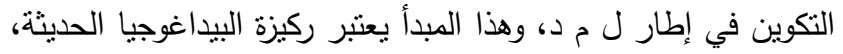
لذا فكون بعض المؤسسات (0 مؤسسات) ترى أن ملائمة هذه ولهي المواضيع لاحتياجات الطلبة ضعيفة أو غير مرضية فهي إجابة غير

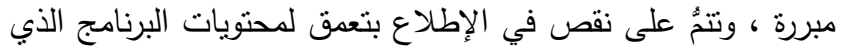

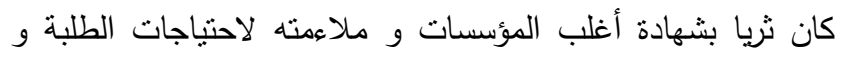

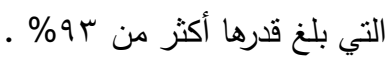
السؤال السابع: مستوى مشاركة الأساتذة الجدد: مستوى مشاركة الأساتذة كانت جد مشجعة فكلها كانت بين

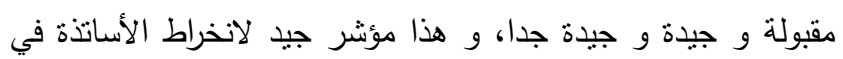

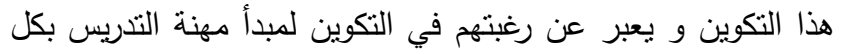

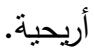

السؤال الثامن: تقييم مستوى الجهود المبذول من طرف خلية

تعتبر خلية التكوين هي القلب النابض لهذه العملية الجديدة و

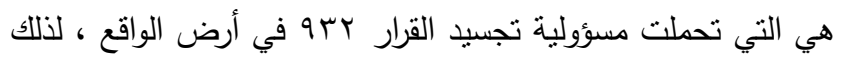

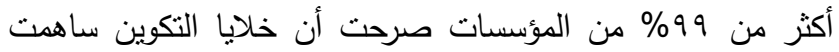

بشكل فعال و بذلت جها تراوح بين المقبول و الجيد و الجيد جدا.

ه. تكرارات الإجابات على أسئلة التقييم المنهجي للتكوين.

الجدول رقم (^•): يوضح الإجابات على أسئلة التقييم المنهجي للتكوين.

\begin{tabular}{|c|c|c|c|c|c|c|}
\hline \multicolumn{6}{|c|}{ درجات التقييم } & \multirow{2}{*}{ المعايير } \\
\hline جيد & جيد & صحيح & مرض & ضعيف & & \\
\hline ir & $\leqslant 4$ & ir & 1 & 1 & النكرار & \multirow{2}{*}{ الكفاءات المهنية و تطوير } \\
\hline$\left|V_{6} \wedge\right|$ & 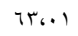 & $\mid V_{6}(\Lambda)$ & $1.5 \mathrm{~V}$ & 1 & النسبة & \\
\hline ro & ra & 1 & 1 & 1 & النكرار & \multirow{2}{*}{ 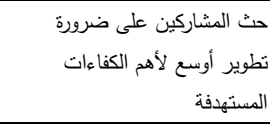 } \\
\hline rs.ro & or,\&r & 1.697 & 1 & $1, \mathrm{TV}$ & النسبة & \\
\hline iv & rY & $r r$ & $v$ & 1 & النكرار & \multirow{2}{*}{ 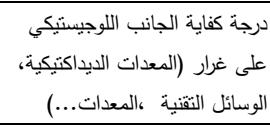 } \\
\hline rritq & ro.4T & $r 1.01$ & 9.09 & 1 & النسبة & \\
\hline$r 4$ & $r$ & iv & 9 & 1 & التكرار & \multirow{2}{*}{ 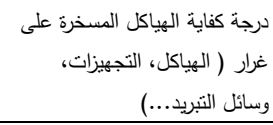 } \\
\hline ro.tr & $r A_{.}, Y Y$ & rr.rq & IT.Tr & 1 & النسبة & \\
\hline$r v$ & $r r$ & 11 & $r$ & 1 & النكرار & \multirow{2}{*}{ وفترنه نشر وتوزيع الوثائق التي } \\
\hline 0.611 & $r 1.01$ & $10 . . \mathrm{V}$ & r.V & 1 & النسبة & \\
\hline$\leq 0$ & $r \varepsilon$ & $r$ & 1 & 1 & النكرار & \multirow{2}{*}{ نوعية العموم،التكوين مهم و ذو } \\
\hline $71,7 \varepsilon$ & rr،A1 & £.। & $1, \mathrm{TV}$ & 1 & النسبة & \\
\hline$r v$ & rA & $v$ & 1 & 1 & النكرار & \multirow[t]{2}{*}{ على العوم، النكوين وظيفي وفعال } \\
\hline 0.611 & TA.TT & 9.09 & $1 . \mathrm{TV}$ & 1 & النسبة & \\
\hline
\end{tabular}

السؤال الأول: مستوى اكتساب و تطوير الكفاءات المهنية: مؤسسة واحدة فقط تعتبر مستوى اكتساب و نطوير الكفاءات المهنية غير مرض، أما باقي المؤسسات فهي تقر أن المستوى كان

\begin{tabular}{|c|c|c|c|c|c|c|}
\hline$r T$ & TV & ri & $r$ & 1 & التكرار & \multirow{3}{*}{ تأهيل الأساتذة المعينين النكوين لمستوى } \\
\hline$r ., 1 \leqslant$ & r4.99 & YAYY & $Y, Y<$ & $1, \pi Y$ & لان. & \\
\hline & & & & & & \\
\hline$r$. & YA & $r$. & $\varepsilon$ & 1 & التكرار & \multirow{2}{*}{ لاحتياجات الطلبة } \\
\hline Tr. & 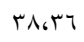 & Trqs. & $0, \leqslant 1$ & $1, \mathrm{rV}$ & النسبة & \\
\hline rq & $r$. & $1 \leqslant$ & 1 & 1 & التكرار & \multirow{2}{*}{ الجددى مشاركة الأساتذة } \\
\hline$r q . v r$ & $\leqslant 1,1$. & 19.11 & 1 & 1 & النسبة & \\
\hline r & $r r$ & v & 1 & 1 & التكرار & \multirow{2}{*}{ التكبذول من طرف خلية } \\
\hline$\{0, r\}$ & $\varepsilon r_{c} \wedge \varepsilon$ & 9.09 & 1 & $1, \pi \mathrm{V}$ & النسبة & \\
\hline
\end{tabular}

السؤال الأول: نحقق الأهداف المحددة للتكوين:

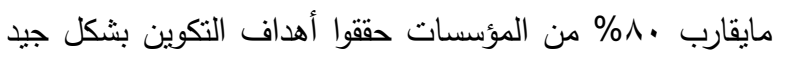
و جيد جدا، فيما هنالك مؤسسة واحدة ليست راضية عن الأهداف الني حقتهها، و تبقى ظروف التكوين و مدته والمصادقة على قوائم الأساتذة

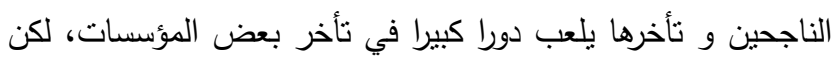
أغلبها حققت الأهداف المسطرة في هذا التكوين.

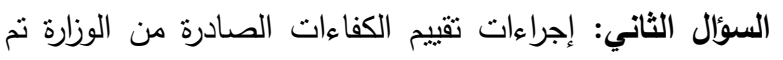

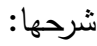
ما يقارب \& \&\% من المؤسسات الجامعية قامت بشرح دليل تقييم

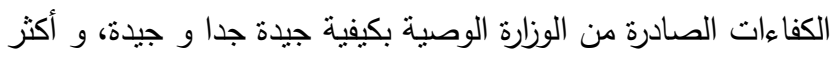

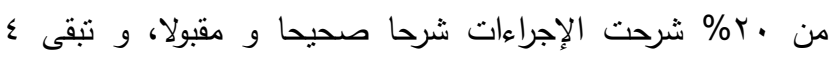

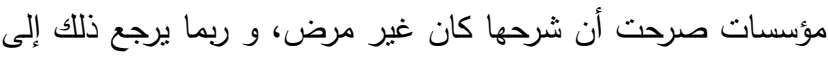
عدم تعود هذه المؤسسات على منل هذه الثبكات التقييمية. السؤال الثالث: إجراءات تقييم الكفاءات الصادرة من الوزارة نم تطبيقها: غالبية المؤسسات الجامعية طبقت إجراءات تقييم الكفاءات بالصورة الموضحة من الوزارة الوصبة، حيث أن نسبة الذين طبقوها

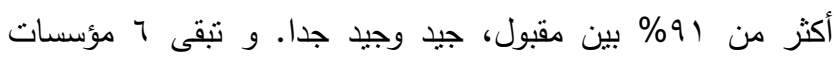

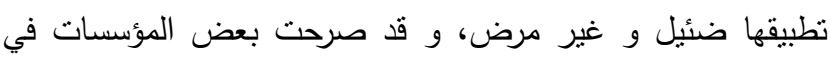
تقاريرها أن شبكات الثقييم كانت معقدة و كثيرة. السؤال الرابع: المناخ ملائم للتكوين:

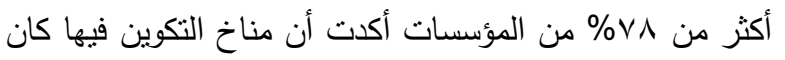

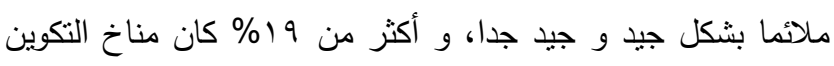

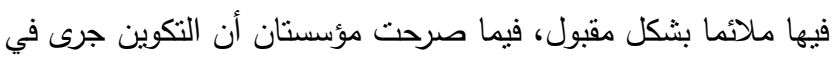

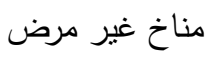
السؤال الخامس: ملائمة التكوين لمستوى تأهيل الأساتذة المعينين حديثا:

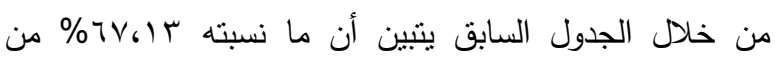
المؤسسات صرحت أن التكوين كان ملائما بصفة جيدة و جيدة جدا

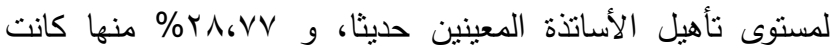
الملائمة مقبولة، فيما أكدت r مؤسسات جامعية أن تلك الملائمة كانت غير مرضية أو ضعيفة. 
ז. كرارات الإجابات على أسئلة تقييم النشاطات الفرعية.

الجدول رقم (9 •): يوضح الإجابات على أسئلة تقييم النشاطات الفرعية.

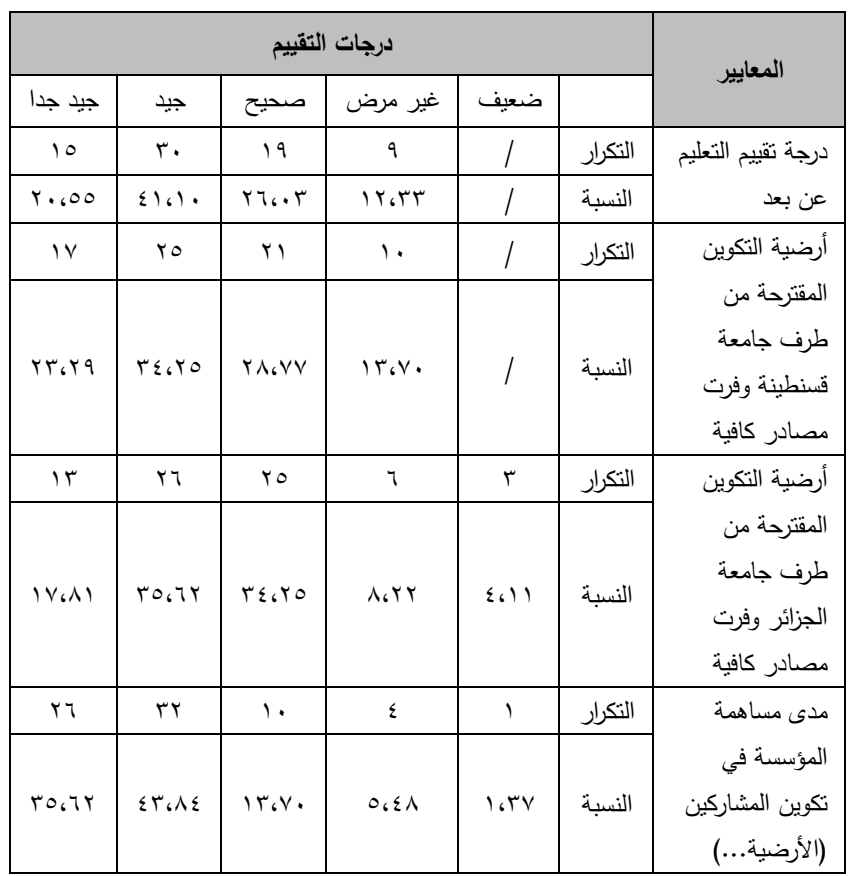

السؤال الأول: درجة تقييم التعليم عن بعد:

7\%، آ7\% من المؤسسات الجامعية نرى أن التعليم عن بُعد كان

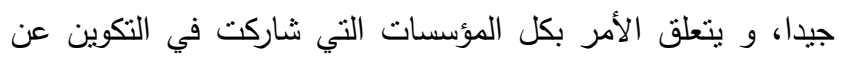

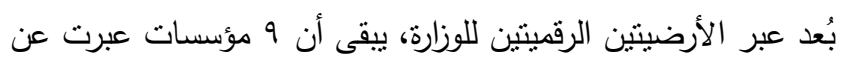

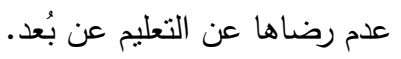

السؤال الثاني: أرضبة التكوين المقترحة من طرف جاندة

قسنطينة وفرت مصادر كافية:

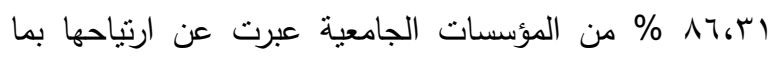

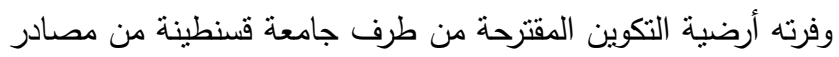

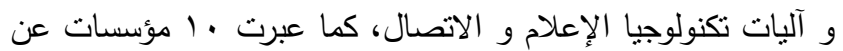

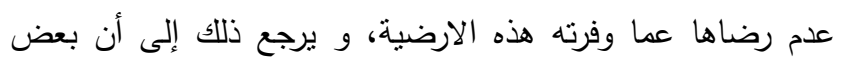

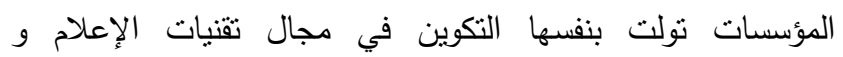

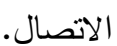

السؤال الثالث: أرضية التكوين المقترحة من طرف جامعة الجزائر وفرت مصادر كافية: المال

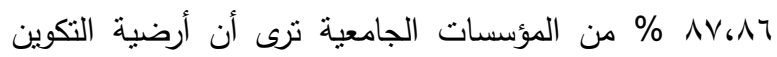

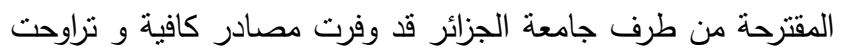
الاستجابة على الاستبيان بين (صحيح، جيد، جيد جدا)، وهذا بدل

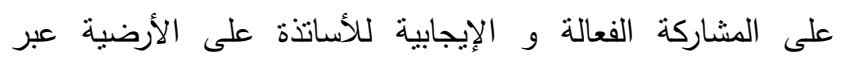
منتدياتها و الاطلاع على الوثائق والفيديوهات المتنوعة التي شارك في الإنه

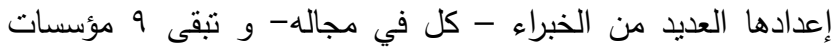

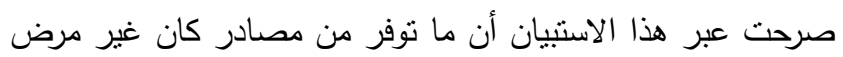

مقبولا بنسبة أكثر من VIV\% ، و مستوى جيد و جيد جدا بنسبة . \%八. ،八

السؤال الثاني: حث المشاركين على ضرورة تطوير أوسع لأهم الكفاءات المستهدفة: من الناحية المنهجية فإن الأساتذة المكونين يدعون في كل مناسبة الأساتذة الجدد الى ضرورة تطوير كفاءاتهم و صقل خبراتهم حتى يتمكنوا من الاضطلاع بالمهام الموكلة إليهم من تدريس و مرافقة

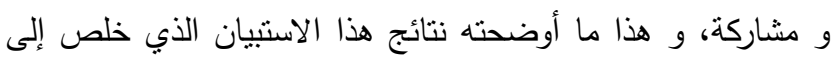

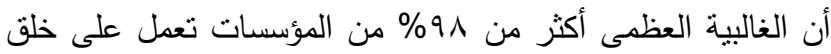
جو من المبادرة الذاتية للأساتذة لنطوير كفاءاتهم. السؤال الثالث: درجة كفاية الجانب اللوجيستيكي على غرار (المعدات الديداكتيكية، الوسائل التقنية ، المعداتية...):

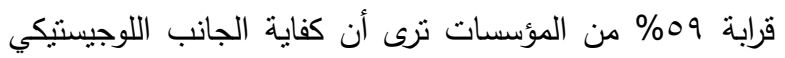

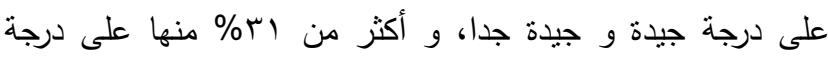
مقبولة من الكفاية ، و تنقى V مؤسسات عبر راضية عن الجانب

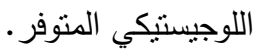
السؤال الرابع: درجة كفاية الهياكل المسخرة على غرار (الهياكل،

$$
\text { التجهيزات، وسائل التبريد...): }
$$
من خلا الجدول السابق يتبين أن 9r،ء؟ب\% من المؤسسات

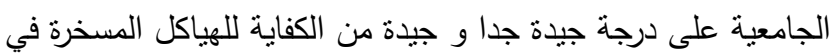

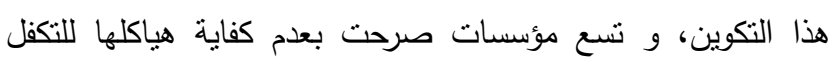

$$
\text { بتكوين الأساتذة الحديثي النوظيف. }
$$

السؤال الخامس: مستوى نشر وتوزيع الوثائق التي وفرتها الوزارة:

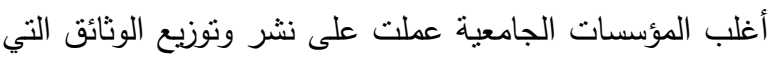

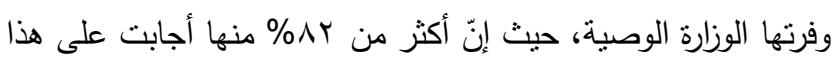

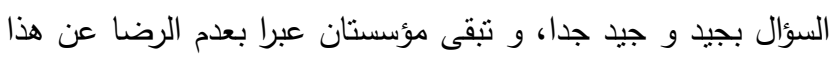
التوزيع دون ذكر سبب ذلك في التقارير النهائية.

السؤال السادس: على العموم،التكوين مهم و ذو نوعية:

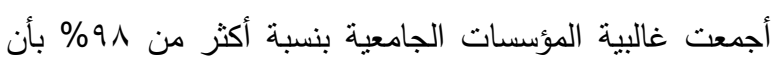

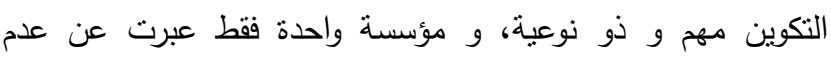
رضاها عن أهية و نوعية هذا التكوين التي لم ترفق تفسيرا لذلك عبر التقرير النهائي. السؤال السابع: على العموم،التكوين وظيفي وفعال: في الأخير ترى أكثر من 91\% من المؤس العابسات الجامعية أن

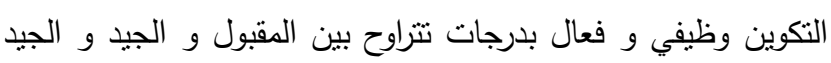
جدا، و أن مؤسسة واحدة فقط عبرت عن عدم الرضا إزاء وظيفية و

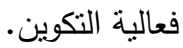


م د بكيفية جيدة و جيدة جدا و 77، ع\% بدركونه بشكل صحيح و

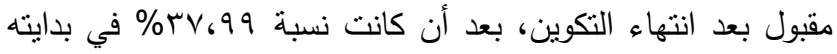

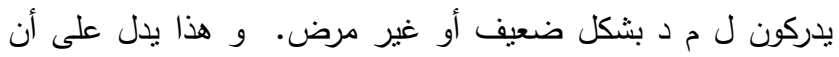

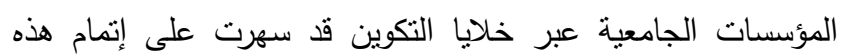
العملية بكل ما أتيح لها من موارد مادية و بشرية. السؤال الثالث: مدى إدرالك المشاركين للمقاربة بالكفاءات:

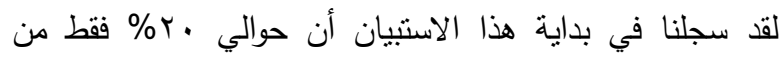
المؤسسات صرحت أن إدراك المشاركين للمقاربة بالكفاءات كانت بشكل جيد و جيد جدا، و أن حوالي 0؛\% منها كان إدراكها ضعيفا أو غير مرض لهذه المقاربة الحديثة، و بعد تلقي المشاركين للتكوين اللازم استتادا للقرار بrو فقد ققزت نسبة المؤسسات التي ترى أن

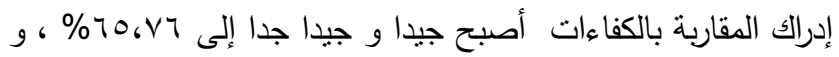

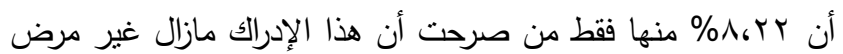
، و هذا طبيعي إذا نظرنا إلى حداثة المقاربة و تعقدها و تشعب جوانبها، و عدم خبرة المشاركين في مجال تطبيق هذه المقاربة. السؤال الرابع: مدى معرفة المشاركين بالنصوص:

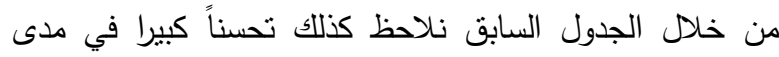
معرفة النصوص المنظمة للتعليم العالي، حيث عبر سه،؛و\% من المؤسسات الجامعية عن معرفتهم بالنصوص بشكل صحيح، جيد و جيد جدا، بخلاف بداية التكوين التي سجلت به مؤسسات التعليم

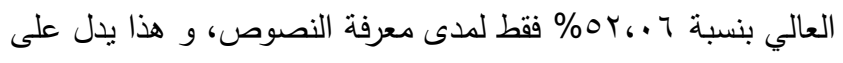
أن المكونين اجتهدوا في إيراز أغلب النصوص التي يحتاجها

المشاركون في حياتهم المهنية.

ثالثا: الصعويات المسجلة أثناء التكوين:

المقاربة بالكفاءات مهمة لكن الأساتذة الموظفين حديثا لم بتمكنوا من استيعابها بالشكل الصحيح، وذلك لحداثة عهدهم بها من جهة، وتباين تخصصاتهم من جهة أخرى. الحجم المكثق للبرامج (r موضوعا) أثر على الالتزامات

البيداغوجية للأساتذة حديثي التوظيف. هناك تداخل بالنسبة للأساتذة بين التكوين الإقامي في

$$
\text { الجامعات و التكوبن عن بُعد. }
$$

\section{رابعا: المقترحات الممكنة:}

لقد تتوعت النشاطات و الثروط التي تراها مؤسسات التعليم العالي ضرورية من أجل إدماج أحسن للأستاذ المعين حديثا داخل مؤسسته، و هي خلاصة سنة كاملة من التكوين و نتيجة الخبرة المستقاة من خلال منابعة هذا التكوين و رصد إيجابيات ثتفيذه و سلبياته، و نلخص مجمل المقترحات فيما يلي:
السؤال الرابع: مدى مساهمة المؤسسة في تكوين المشاركين

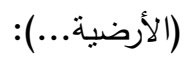

تعتبر الأرضية الرقمية للمؤسسة الجامعية مجالا تطبيقيا لما تعلمه الأساتذة الموظفون حديثا عبر الأرضينتين السابقتين و قد أدلت 71، 19\% من المؤسسات أنها ساهمت في تكوين المشاركين عبر أرضيتها و الوسائل المتاحة لها بشكل (مقبول و جيذ و جيد جدا)، فيما صرحت ع مؤسسات أنها ساهمت بشكل غير مرض، و مؤسسة واحدة أكدت عبر هذا الاستبيان أن مساهمتها كانت ضعيفة كونها لا تملكك مركزا للتعليم عن بُعد و التي بدأت كذلك في التكوين في شهر ماي V V r r كما ورد في التقرير الخاص بها.

v. . كرارات الإجابات على أسئلة التقييم النهائي للتكوين.

\begin{tabular}{|c|c|c|c|c|c|c|}
\hline \multicolumn{5}{|c|}{ درجات التقييم } & \multirow{2}{*}{\multicolumn{2}{|c|}{ المعايير }} \\
\hline جيد & جيد & صحيح & 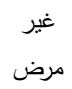 & ضعيف & & \\
\hline זr & rs & $r$ & 1 & 1 & التكرار & \multirow{2}{*}{$\begin{array}{r}\text { التنكوين المشاركين } \\
\text { بالتكواق }\end{array}$} \\
\hline$\{0, r)$ & Or..o & $r_{6} V \varepsilon$ & 1 & 1 & النسبة & \\
\hline 19 & ru & 11 & 1 & 1 & التكرار & \multirow{2}{*}{ 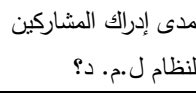 } \\
\hline rY..T & $\sum 9, \pi Y$ & $r \leq .74$ & 1 & 1 & النسبة & \\
\hline $1 \varepsilon$ & $r \varepsilon$ & 19 & 1 & 1 & التكرار & \multirow{2}{*}{ 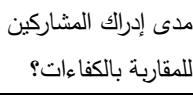 } \\
\hline 19.11 & $\sum 7,01$ & r9.. T & A.rY & 1 & النسبة & \\
\hline IV & r & r) & $\varepsilon$ & 1 & النكرار & \multirow{2}{*}{ بالنصوصى معرفة المشاركين } \\
\hline rr, rq & $\varepsilon r_{6} \leqslant V$ & YA.VY & $0, \varepsilon \wedge$ & 1 & النسبة & \\
\hline
\end{tabular}
الجدول رقم ( • (): يوضح الإجابات على أسئلة بيان نهاية التكوين.

بعد اسنكمال مجريات التكوين للمؤسسات الجامعية المشاركة أعبد طرح التساؤلات التي طرحت أولا في هذا الاستبيان لتقدير مدى تقدم هذا التكوين الخاص بالأساتذة حديثي التكوين فكان تقييم الإجابات كما هو موضح في الجدول السابق نتتاوله في هذا العرض

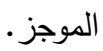
السؤال الأول: التحاق المشاركين بالتكوين: من خلال الجدول السابق نرى أن التحاق المشاركين بالتكوين كان كاملا و يترواح بين الخيارات الثلاثة ( صحيح، جيد، جيد جدا) بخلاف ما كان عليه في الأول حيث سجلنا مؤسسنين صرحت بـ غير راض عن التحاق المشاركين بالتكوين، و هذا يدل على أن التكوين أخذ على محمل الجد و أن المؤسسات كلها اهتمت بتطبيق القرار ץبو لأهميته البالغة في دمج الأساتذة الحديثي التكوين في محيطهم الجامعي وتزويدهم بكل ما يحتاجونه لممارسة صحيحة لمهنة

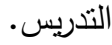
السؤال الثاني: مدى إدراك المشاركين لنظام ل.م. د: أوضح الجدول السابق كذلك أن كل المؤسسات الجامعية أعربت عن ارتياحها إزاء إدراك الأساتذة المتكونين لنظام ل م د، حيث ما نسبته هץ، \% من المؤسسات أكدت أن المشاركين يدركون نظام ل 
والمتابعة ، ونسنطيع القول في النهاية إنّ الأهداف التي سطرت من

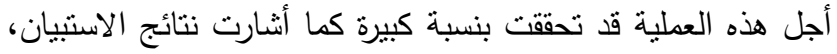
رغم تأخر بعض المؤسسات الجامعية في إرسال الاستيان لتنمين

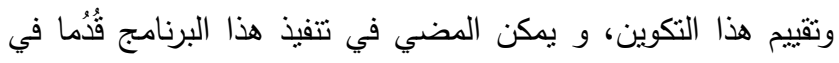

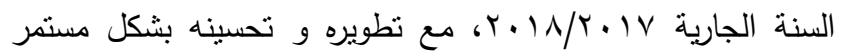
حتى يتلاءم مع منطلبات مهنة التدريس في ضوء معايير النوعية وضمان جودة التعليم العالي.

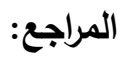

I. حرز الله عبد الكريم، حوشين مصطفى، كمال

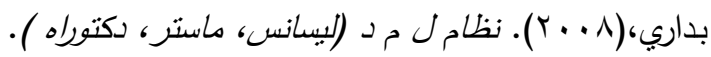

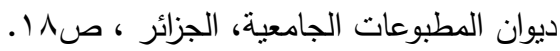
r. العبادي أحمد، قاسم عمر (2017). نماذج تقييم تكوين الموارد البشرية في المنظمة بالتركيز على نموذج كيرك العيد باتريك، مجلة البشائر الاقتصادية، المجلد الثالث، العدد:

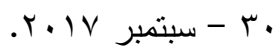
r. كمال بداري، فارس بوباكور، عبد الكريم حرز الله،

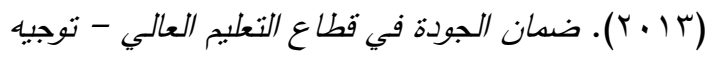
و إنجاح التقبيم الذاتي. ديوان المطبوعات الجامعية،

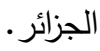

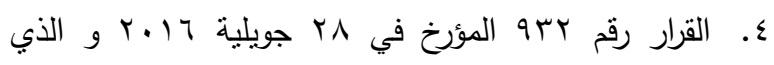
يحدد كيفيات تنظيم المرافقة البيداغوجية لفائدة الأساتذة

$$
\text { الباحثين حديثي التوظيف. }
$$

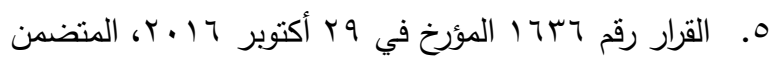

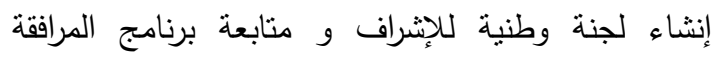
البيداغوجية لفائدة الأستاذ الباحث.

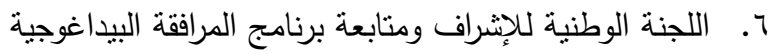

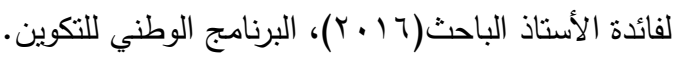

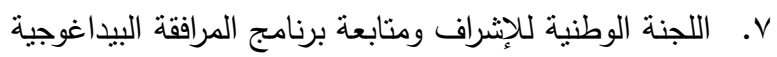

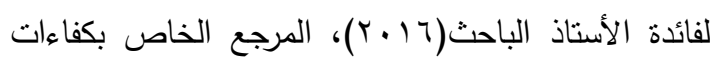

$$
\text { الأساتذة -الباحثين حديثي التوظيف. }
$$

\section{Translated References :}

1. Alabadi.A, Akasim.O, The Evaluation Models of the Composition of Human Resources in the Organization Focusing on the Model Kirk Patrick, Al - Bashaer Economic Journal, Volume 3, Issue: 30 September 2017.

2. Baddari, Boubakeur.F, Harzzellah.A.K, Quality Assurance in the Higher Education Sector - Guidance and success of selfevaluation. University Press, Algeria, (2013).
مقترحات خاصة بالبرنامج:

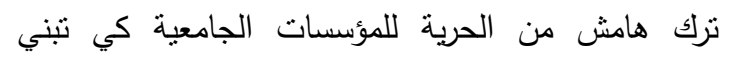
برامجها في ضوء القرار بrو وفق مانق ما تملكه من موارد مادية و بشرية ولوجيستية. تقسيم الأساتذة حسب المبادين، والتفكير في بناء برنامج

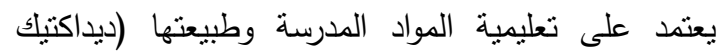
العلوم، ديداكتيك الهندسة، ديداكتيك علم الاجتماع...).

\section{مقترح خاص بطريقة التكوين:}

تكوين المكونين و أعضاء خلية متابعة النكوين البيداغوجي، بلقاءات محلية، جهوية أو وطنية.

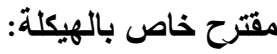

تخصيص هيئة دائمة متفرغة لإدارة التكوين و المرافقة البيداغوجية وتكون ضمن الهيكلة الرسمية للمؤسسة.

مقترحات خاصة بمدة التكوين:

تمديد فترة التكوين و المرافقة البيداغوجية إلى سنتين. الاعتماد على تتظيم التكوين في فترة مغلقة و مركزة قبل الانطلاق في عملية التدريس.

\section{مقترح خاص بالأعباء البيداغوجية:}

• اعفاء الأستاذ حديث التكوين من كل الأعباء البيداغوجية

لحين الانتهاء من فترة التكوين.

مقترحات أخرى:

إعطاء أهمية لتقييم مسار تكوين الأستاذ و إدراج النجاح

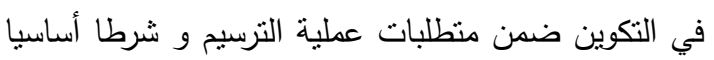

فيه.

تعميم النكوين و المرافقة البيداغوجية على باقي الأساتذة الراغبين في التكوين و طلبة الدكتوراه.

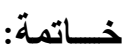

في ختام هذا الثقرير التقييمي نشير إلى أن الدجهودات التي

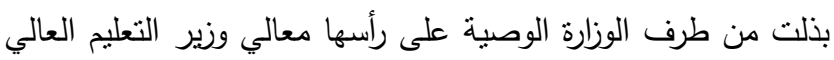

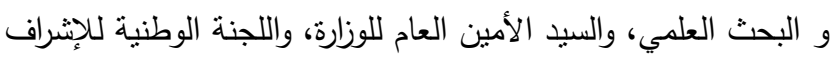
ومتابعة التكوين، وكذا مديرو المؤسسات الجامعية و منسقو خلايا التكوين، ومسيرو الأرضيتين الرقينين، كانت مجهودات كبيرة نثن

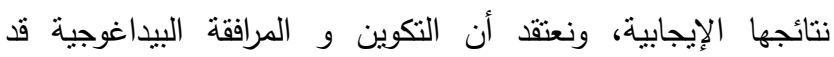
وضعت على السكة الصحيحة، وأكبر دليل على ذلك التقييم الذي بني

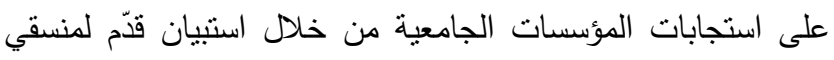
خلايا التكوين على مستوى كل مؤسسة للتعرف على مدى فاعلية هذا

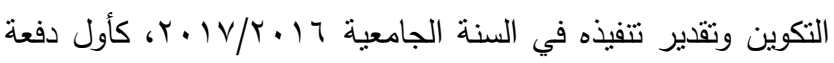
بعد صدور القرار الوزاري رقم كبهو و تشكيل اللجنة الوطنية للإثراف 
3. Herz Allah Abdul Karim, Hushin Mustafa, Kamal Badari, (2008) LMS System (Bachelor, Master, PhD). University, Algeria, p. 18.

4. Ministry of Higher Education and Scientific Research, Decree 1636 of October 29, 2016 included the establishment of a national committee to oversee the follow-up and the accompanying teaching program for the benefit of the research professor .

5. Ministry of Higher Education and Scientific Research, Decree No. 932 of July 28, 2016, which defines the arrangements for organizing pedagogical support for newly recruited research professors.

6. National Commission for the Supervision and Follow-up of the Pedagogical Accompaniment Program for the Researcher Professor (2016).

7. National Committee for the Supervision and Follow-up of the Pedagogical Accompaniment Program for the Researcher Professor (2016), National Training Progra 